\title{
Biocompatibility and osteopromotor factor of bovine integral bone-a microscopic and histometric analysis
}

\author{
Ana Paula Farnezi Bassi ${ }^{1}$, Vinícius Ferreira Bizelli ${ }^{2}$, Renata Bianco Consolaro ${ }^{3}$, \\ Paulo Sérgio Perri de Carvalho ${ }^{4}$
}

${ }^{1}$ Department of Diagnosis and Surgery, São Paulo State University-UNESP, School of Dentistry, Araçatua, São Paulo, Brazil; ${ }^{2}$ Department of Diagnosis and Surgery, São Paulo State University-UNESP, School of Dentistry, Araçatua, São Paulo, Brazil; ${ }^{3}$ University Center of AdamantinaUNIFAI, Araçatua, São Paulo, Brazil; ${ }^{4}$ Department of Stomatology and Oral Biology-Bauru Dental School, USP-University of São Paulo, Bauru, São Paulo, Brazil

Contributions: (I) Conception and design: APF Bassi, PSP de Carvalho; (II) Administrative support: APF Bassi, RB Consolaro; (III) Provision of study materials or patients: APF Bassi, PSP de Carvalho; (IV) Collection and assembly of data: RB Consolaro, VF Bizelli; (V) Data analysis and interpretation: RB Consolaro, VF Bizelli; (VI) Manuscript writing: All authors; (VII) Final approval of manuscript: All authors.

Correspondence to: Vinícius Ferreira Bizelli. Univ. Estadual Paulista (UNESP), Araçatuba Dental School, Department of Diagnosis and Surgery, Estadual Paulista (UNESP), Araçatuba Dental School, Rua José Bonifácio, 1193, 16015-050, Araçatuba, São Paulo, Brazil. Email: v.bizelli@unesp.br.

Background: The objective of this study was to evaluate the biological properties, biocompatibility, and osteopromotor factor of integral bone of bovine origin implanted in critical defects of rat calvaria and the subcutaneous plane of rats.

Methods: The study was divided into two stages. For the first stage, 24 rats were divided into two groups of 12 animals: group GC, in which the critical defect was filled only by clot, and group GO, in which the defect was filled with particulate biomaterial, and the analysis performed at 30 and 60 days postoperatively. For the second stage, 16 rats were divided into two groups of eight animals: the GOP group, in which the biomaterial in its particulate form was inserted in the subcutaneous plane, and the GOB group, in which the block biomaterial was inserted in the subcutaneous; and the analysis performed at 15 and 45 days postoperatively.

Results: The histological and histometric results of the calvaria demonstrated that the biomaterial induced a foreign body reaction over the entire length of the defect and around the particles and was not able to induce bone neoformation. Statistically, no difference was observed for the time, biomaterial, and time $x$ biomaterial parameters $(\mathrm{P}>0.05)$. Subcutaneous microscopic examination of the pieces obtained at 15 days showed an inflammatory reaction around the particles of the material with the presence of giant cells and at 45 days, and a reduction in the inflammatory reaction and presence of fibrous connective tissue around the particles was observed with the presence of giant cells, and for the block biomaterial, connective tissue was present in the trabecular spaces. There was no evidence of ectopic bone formation.

Conclusions: The biomaterial, despite being biocompatible, do not promote bone neoformation.

Keywords: Xenogenic; osteopromotor; biocompatibility; integral bone; guided bone regeneration

Received: 31 March 2021; Accepted: 29 July 2021; Published: 10 December 2021.

doi: 10.21037/fomm-21-42

View this article at: https://dx.doi.org/10.21037/fomm-21-42

\section{Introduction}

Biomaterials are frequently used as complementary therapies, especially for the installation of implants, alveolar filling, sinus grafts, or guided bone regeneration (ROG)
(1-3). However, knowing the biological potential of each material is of fundamental importance to indicate their use in different clinical situations; thus, observing their biological behavior in contact with different tissues is 
essential $(4,5)$.

In 2008, aimed to unify and expand the concepts of biocompatibility authors proposed that a biomaterial should perform the desired function in relation to medical therapy, without inducing any undesirable local or systemic effects to the beneficiary of the therapy, but generate cellular responses and tissues more beneficial in that specific situation and optimize the clinically relevant responses of that therapy (6). In this context, it can be determined that biocompatibility is a property that materials must possess to enable their use in a biological system without causing adverse reactions or preventing the tissue differentiation characteristic of the implantation site (7). Acute and chronic inflammatory responses and the immune response are among the adverse reactions that can be identified clinically with biomaterials $(8,9)$.

Biomaterials can have different origins and can be heterogeneous or xenogenic in nature, most commonly being obtained from cattle, pigs, or goats (10-12). These biomaterials, except autogenous biomaterials, play a fundamental role in filling the spaces presented by bone defects, without physiological incorporation $(13,14)$. They present only osteoconductive activity; it has also been reported, including by the companies that produce biomaterials or bone substitutes, that their products are only osteoconductors. Additionally, there are some claims that some demineralized biomaterials are also osteoinductive (15). However, there are questions about the osteoinductive function of most bone substitutes.

To resolve the doubts regarding the biological properties of integral bovine bone, the implantation of integral bovine bone was carried out in critical defects in rats cavlaria and in the subcutaneous tissue to study the osteoprotomor potential, osteoinduciton capacity and biocompatibility of the biomaterial (16).

We present the following article in accordance with the ARRIVE reporting checklist (available at https://fomm. amegroups.com/article/view/10.21037/fomm-21-42/rc) (17).

\section{Methods}

\section{Animal model}

The research was approved by the Animal Experimentation Ethics Committee of the Araçatuba Dental School UNESP (CEUA) under the protocol 2011-00893, in compliance with the National Council for the Control of Animal Experimentation (CONCEA), national guidelines for the care and use of animals.

\section{Biomaterial}

OrthoGen (Baummer S.A., Mogi Mirim, Brazil) is produced from bovine origin, a heterogeneous biomaterial, is composed of an organic portion of collagenous proteins (25-30\%) and a mineral portion of hydroxyapatite $(65-70 \%)$. There are two of presentation, particulate and block with a degradation time of approximately six months.

\section{Study design}

A total of 40 adult male (3-4 months) rats (Rattus norvegicus, Albinus, Wistar) weighing between 300 and $400 \mathrm{~g}$ were used. Throughout the experimental period, the animals were provided a solid and balanced food ration (Ração Ativada Produtor, Moinho Primor S.A), with water provided ad libitum in the vivarium of the Araçatuba Dental School UNESP. Day and night cycles and controlled temperature were maintained. Three animals were housed per cage.

For the first stage of the study, 24 animals were randomly divided into two groups of 12 animals: group GC (clot) in which the bone defect was filled only with clot and group GO (Orthogen) in which the defect was filled with bovine integral bone. All the defects were protected with a bovine bone cortical membrane (GenDerm ${ }^{\circledR}$ Baummer S.A). On the day of the surgery, a critical bone defect of 8 $\mathrm{mm}$ in diameter was made in the center of the calvaria in all animals (18). The animals were euthanized at 30 and 60 days after the surgery.

For the second stage of the study, 16 animals were randomly divided into two groups of 8: GOP group (Orthogen particle), in which the bovine integral bone was implanted in a collagen matrix and introduced subcutaneously, and the GOB (Orthogen block) group, in which a block of bovine integral bone was introduced into the subcutaneous tissue. The animals were euthanized at 15 and 45 days after the surgery (19).

\section{Experimental surgical procedure}

For the two stages of the experiment, the animals went through a 12-hour preoperative fast and were sedated with ketamine hydrochloride (Francotar-Vibrac do Brasil Ltda, São Paulo, Brazil) associated with xylazine (Rompum-Bayer AS-Animal Health, São Paulo, Brazil), at a dosage of 50 and $5 \mathrm{mg} / \mathrm{kg}$, respectively $(4,5,20-22)$. A strict aseptic protocol 

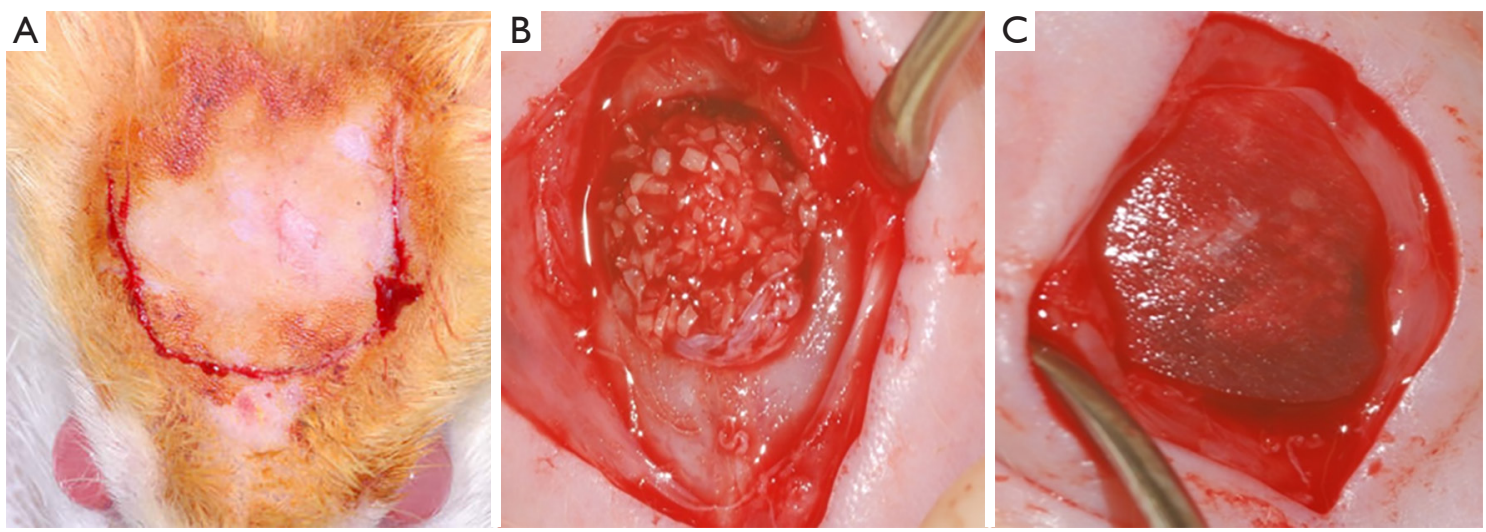

Figure 1 Surgical procedure in rat calvaria. A semilunar incision for access to the calvaria (A); a critical bone defect of diameter 8 mm filled with particulate mineral bovine bone (B); Bovine cortical bone membrane protecting the bone defect, acting as a barrier (C).

was adopted, including sterilization of the instruments used, delimitation of the area to be operated with sterile drapes, and the use of sterile surgical gowns and gloves. All surgical procedures were performed in the operating room of the Vivarium of the Faculty of Dentistry of Araçatuba, UNESP. Prior to each procedure, trichotomy of the region of interest was performed, the region was cleaned with polyvinyl pyrrolidone degenerative iodine (PVPI 10\%, Riodeine Degermante, Rioquímica, São José do Rio Preto) and topical PVPI (PVPI 10\%, Riodeine, Rioquímica, São José do Rio Preto), and sterile fields were affixed.

\section{Surgical critical defect}

A semi-lunar incision of approximately $2 \mathrm{~cm}$ in the occipitofrontal direction was made and the flap was detached (Figure 1A). Subsequently, with the aid of a $7 \mathrm{~mm}$ internal diameter trephine drill (3i Implant Innovations, Inc., Palm Beach Gardens, USA) coupled with low rotation under abundant irrigation with $0.9 \%$ sodium chloride solution (Darrow, Rio de Janeiro, Brazil), a critical surgical defect of external diameter $8 \mathrm{~mm}$ was made in the central portion of the calvaria involving the sagittal suture (18), while maintaining the integrity of the dura mater. Each animal in the GC and GO group received the proposed treatment (Figure 1B), and all defects were protected with the bovine cortical bone membrane (GemDerm ${ }^{\circledR}$ Baummer S.A) (Figure 1C) (13). At the end of the procedure, the soft tissues were carefully repositioned and sutured in planes.

\section{Subcutaneous implantation}

A linear incision of approximately $1 \mathrm{~cm}$ was made in the skin of the dorsal region of the animal following the sagittal line to expose the subcutaneous tissue (Figure 2A,B). Subsequently, the particles of the biomaterial (Orthogen) were inserted into a collagen matrix to be implanted into the tissue (Figure $3 A, B$ ). The block biomaterial was inserted subcutaneously in the other group (Figure $3 C$ ). At the end of the implantation, a simple interrupted suture was performed using mono nylon 4-0 (Ethicon, Johnson \& Johnson).

Each animal received a single intramuscular dose of $0.2 \mathrm{~mL}$ of penicillin G-benzathine (Small Veterinary Pentabiotic, Fort Dodge Saúde Animal Ltda., Campinas, $\mathrm{SP})$ in the immediate postoperative period of the two experimental stages. The animals were euthanized with an anesthetic overdose at the respective experimental times. As an exclusion criterion, it was established that any animal with trans or postoperative surgical complication would be excluded from the sample that was being evaluated $(4,5,20-22)$.

\section{Histological analysis}

The samples collected from the calvaria and the subcutaneous tissue were fixed in a $10 \%$ formaldehyde solution for $48 \mathrm{~h}$, washed in running water for $48 \mathrm{~h}$, decalcified in 20\% EDTA for 5 weeks, dehydrated in a sequence of alcohols, and diaphanized. Subsequently, the calvaries were cut in half in the longitudinal direction, separating the bone defect into two equal parts. The pieces obtained from the two stages of the study were embedded in paraffin and cut into semi-series cuts of $6 \mu \mathrm{m}$ thickness. A total of 10 slides were obtained from each piece and stained with hematoxylin and eosin (H\&E) for descriptive histological analysis and 

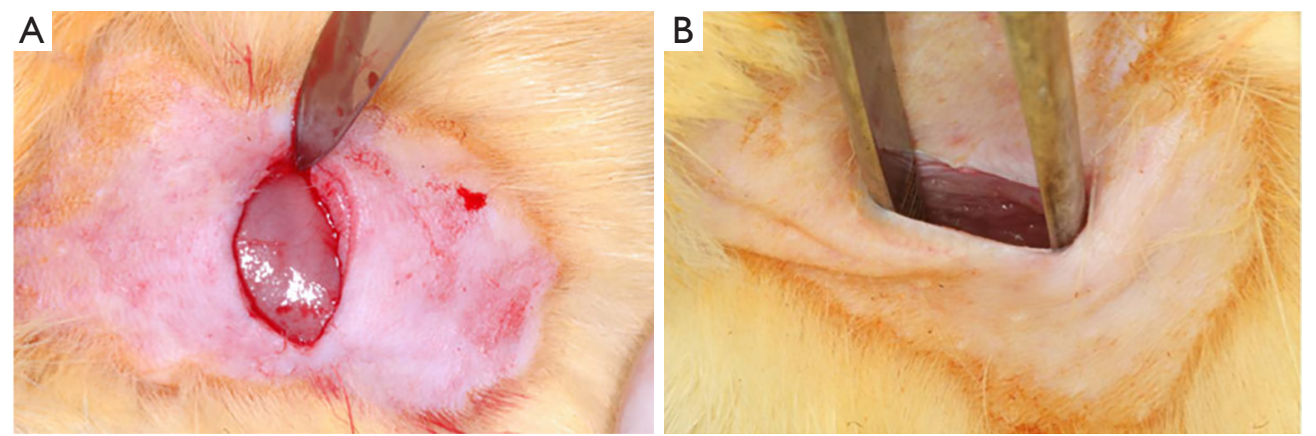

Figure 2 Surgical procedure in the subcutâneous. A linear incision of approximately $1 \mathrm{~cm}$ in the skin to access the subcutaneous tissue (A); divulsion of subcutaneous tissue for the implantation of biomaterials (B).
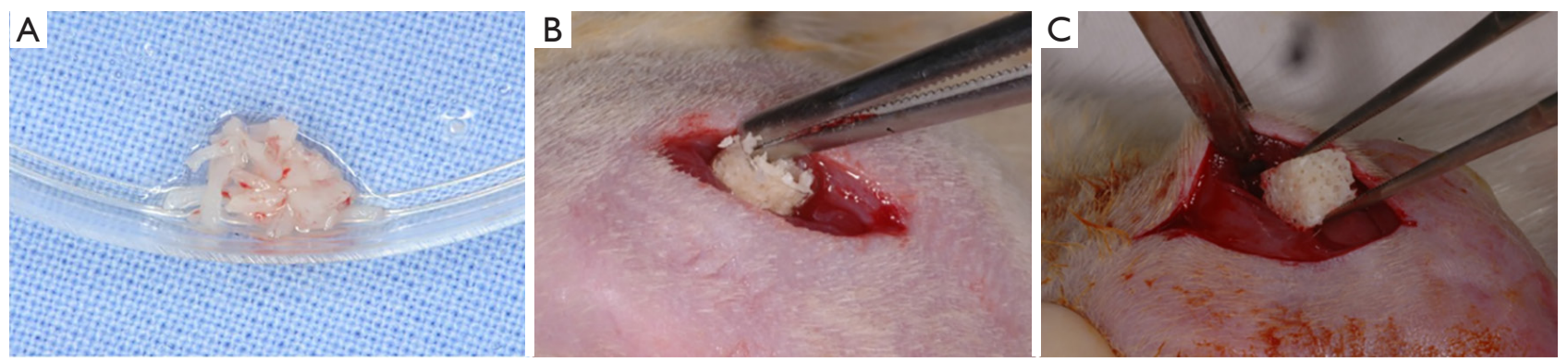

Figure 3 Bovine integral bone in the particulate and block form inserted in the subcutaneous. Particulate bovine integral bone being prepared (A); particulate bovine integral bone inserted in the collagen capsule and implanted in the subcutaneous tissue (B); bovine integral bone block inserted in the subcutaneous tissue (C).

histomorphometric analysis of the calvaria of the newly formed bone tissue. The slides were examined under an Axiookop 2 plus microscope (Carl Zeiss, afrom Germany) and photographed with the Axio Cam HCR (Carl Zeiss, Brazil). Histometry was performed by overlaying the Merz grid, making it possible to establish the amount of bone neoformation (primary outcome) in the GC and GO groups at the two experimental times, tissue response and cell type presente (biocompatiblity) in the GOP and GOB groups at the two experimental times (14,23-26).

\section{Statistical analysis}

The data obtained during the histomorphometric analyses for the amount of newly formed bone of the sample averages were subjected to a normality test to assess the distribution of the samples (Shapiro-Wilk, $\mathrm{P}>0.05$ ). After confirming the normal distribution of the samples, for histomorphometric analyses $(\mathrm{P}=0.156)$, the 2 -factor analysis of variance was used to compare the time, biomaterial, and time $\times$ biomaterial variants. For the analysis of the amount of biomaterial at 30 and 60 days, the normality test was nonparametric; therefore, the Mann-Whitney test $(\mathrm{P}=0.0167)$ was used.

\section{Results}

\section{Histological analysis of the calvarias}

After 30 days of bone repair, new bone formation was observed in the bone stumps of the GC and GO groups. Notably, areas of neoformed bone tissue (AON) with immature bone characteristics were observed in the center of the defect in the GC group, surrounded by an organized connective tissue (CT) that occupied the central region of the defect and membrane fragments $(M)$ (Figure 4A). For the GO group, microscopic sections were examined to reveal the presence of the membrane $(\mathrm{M})$ of young connective tissue (CT), containing macrophages, lymphocytes, vascular neoformation, fibroblasts, and scarce extracellular matrix filling the space between the 

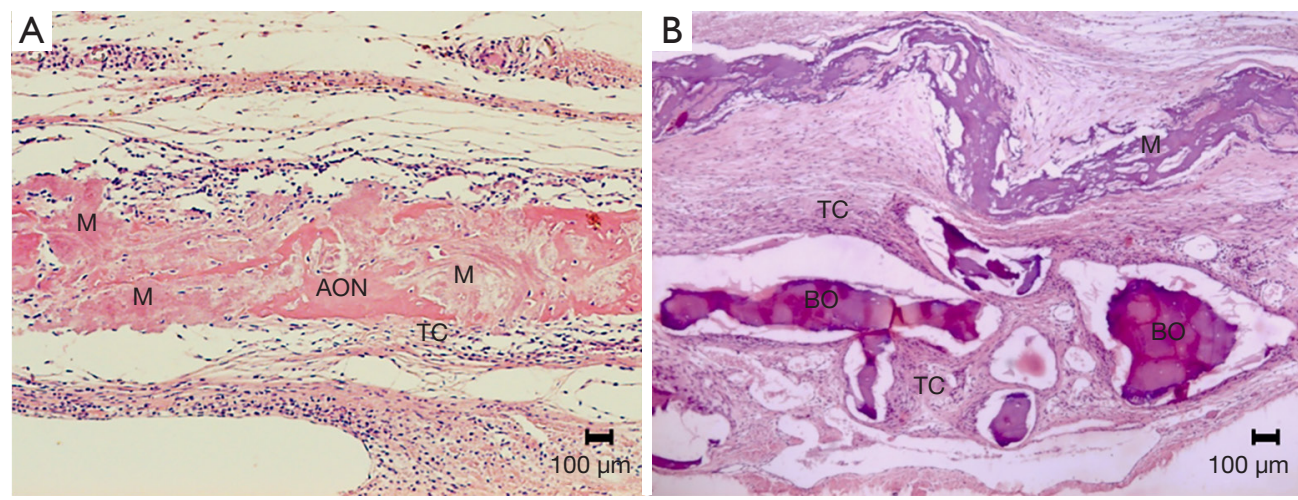

Figure 4 Center of the critical defect at 30 days in the CG group showing areas of immature neoformed bone tissue (AON), surrounded by connective tissue (CT) (A); Center of the critical defect at 30 days in the GO group showing particles of the biomaterial (BO) with varying morphology and sizes and occasionally forming right angles (B). H\&E stain. Magnification of 12.5x.

Table 1 Group OG (orthogen)-microscopic analysis

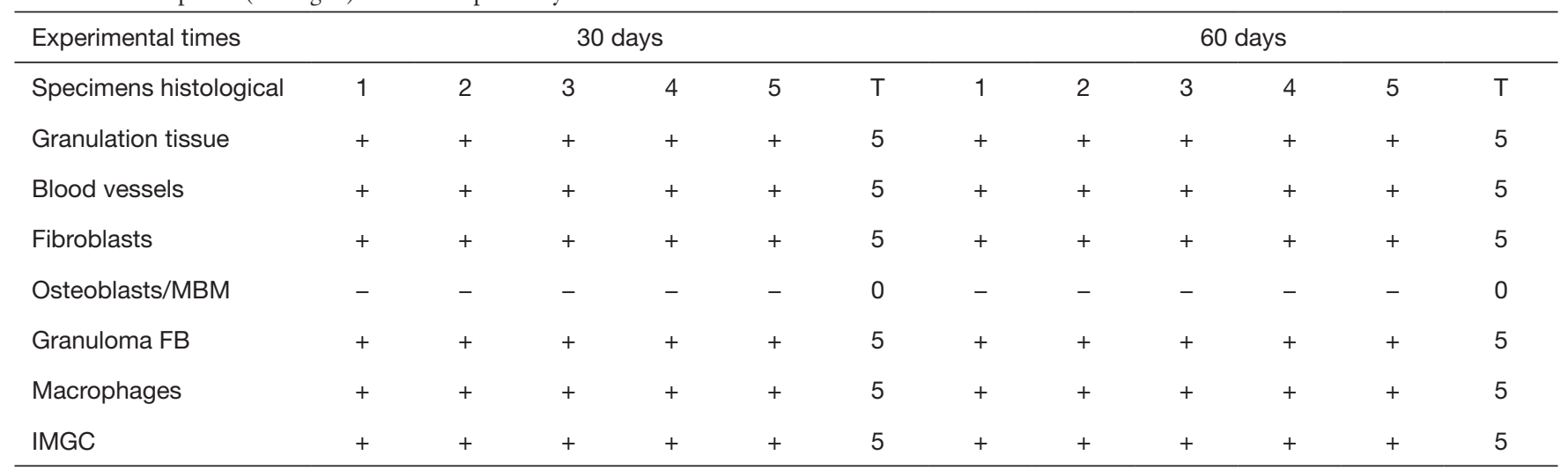

T, total; MBM, mineral bone matrix; FB, foreign body; IMGC, Inflammatory multinucleated giant cells; +, presence; -, absence.

particles of the biomaterial (BO) both in the central region of the wound as well as at the edge of the bone defect. The identifiable particles of the material are basophilic and polyhedral with varying morphologies and sizes, occasionally forming right angles.

A large concentration of macrophages and inflammatory multinucleated giant cells (IMGC) as well as delicate collagen fibers and fibroblasts were observed circumscribing the surface of each particle, characterized as foreign body granulomas. There was no bone neoformation related to the material; additionally, bone neoformation was only noticed in the stumps of the surgical wound, due to the normal process, which was absent in the central region (Figure $4 B$ and Table 1).
At 60 days, the specimens were observed to have small and few spaces containing connective tissue (CT), with mature bone tissue found throughout the defect (TO) in the control group; however, complete defect closure was not observed in any specimen (Figure $5 A$ ), and the bone tissue that was observed was thin. The GO group, as in the previous period, continued to be filled with numerous particles of the biomaterial (BO), following the same microscopic pattern already described; however, the foreign body granuloma reaction observed on the surface of the particles was intensified, with granulomas of the type with foreign bodies being much more established with a more organized fibrous capsule surrounding each particle. Among the particles, the mature connective tissue (CT), 

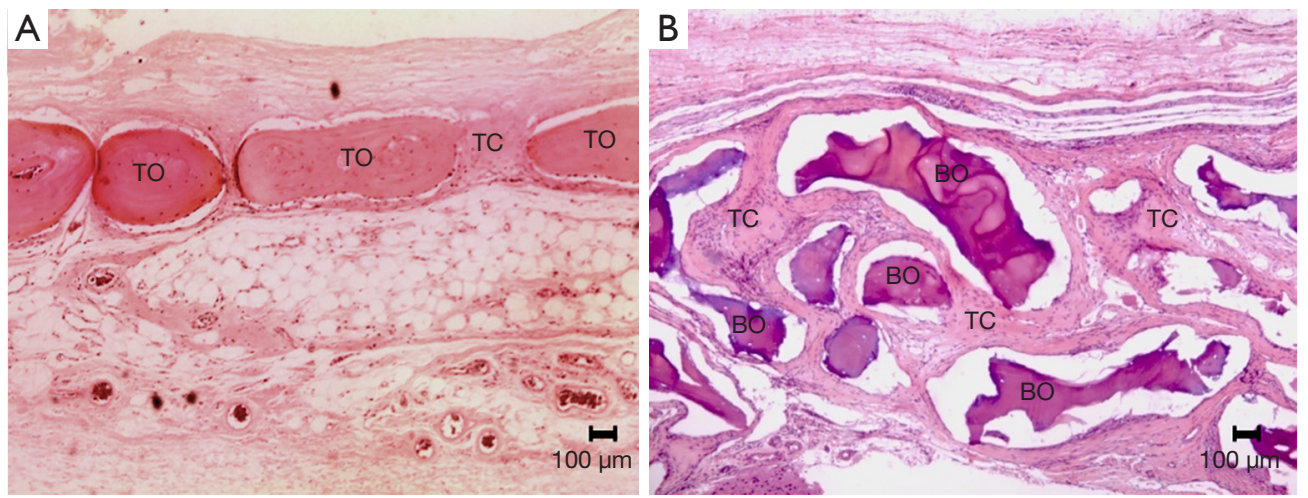

Figure 5 Center of the critical defect at 60 days in the CG group showing mature bone tissue (TO) in all extensions of the defect, except in the center (A); center of the critical defect at 60 days for the GO group showing numerous particles of the biomaterial, with an intensification of inflammatory foreign body reactions, with boundaries of the capsules surrounding the particles of the biomaterial (BO) (B). H\&E stain. Magnification of $12.5 \times$.

containing macrophages, lymphocytes, a lesser amount of vascular neoformation, fibroblasts, and neoformed collagen fibers, was observed. As in the previous period, there was no bone neoformation related to the material; additionally, bone neoformation was only noticed in the surgical wound stumps, due to the normal process, which was absent in the central region (Figure $5 B$ and Table 1).

\section{Histometric analysis}

From the data obtained from the histological analysis of the amount of newly formed bone, it can be observed that the time-variant was not statistically significant $(\mathrm{P}=0.305)$, and neither was the presence of the biomaterial $(\mathrm{P}=0.052)$. In a comparative analysis between the two variants, duration, and biomaterial, there was no statistically significant difference $(\mathrm{P}=0.736)$.

Regarding the amount of biomaterial present at 30 and 60 days, no statistically significant difference was observed, demonstrating that time did not interfere with the amount of biomaterial in the bone defect during the evolution of the repair.

\section{Histological analysis of the subcutaneoous defect}

No remnants of the empty collagen capsules implanted on the backs of the animals were observed at 15 and 45 days.

At 15 days, the particulate biomaterial (BOP) implanted in the muscle plane with cellularized connective tissue (CT) in its vicinity was observed in the GOP group. Connective tissue was observed to be richly vascularized (V) and close to the particles; there was a predominance of loose connective tissue $(\mathrm{CF})$, which is characterized by a greater number of fibroblasts. At a distance from the particles, the connective tissue was fibrous, characterized by the presence of bundles of collagen fibers oriented parallel to the particles (Figure 6A).

For the GOB group, a biomaterial material (BO) was implanted in the muscle plane with loose connective tissue (CF) in the trabecular spaces, and the remaining clot was observed, with an absence of inflammatory infiltrate and loss of connective tissue with vascular proliferation $(\mathrm{V})$ invading the trabecular spaces (ET) in the vascular tissues. In some areas, the development of fibrous connective tissue was observed (Figure 6B).

At 45 days, for the GOP group, the images were similar when compared to the presence of the biomaterial (BO) in the muscular plane; however, the connective tissue (CT) surrounding the implanted material presented with more fibrous connective tissue in the vicinity, a greater amount of multinucleated cells, and areas that suggest resorption of the material (Figure $7 A$ ). In the GOB group, the implanted material was found in the muscular plane, presenting its trabecular spaces (ET) filled with loose connective tissue (CF), with a significant decrease in residual bone (thinner trabeculae). Fibrous connective tissue can be observed in the space between the muscular plane and block of the implanted material. Additionally, the presence of multinucleated giant cells in the vicinity of the implanted material is notable; furthermore, resorption is suggested at the periphery of the material (Figure $7 B$ ). 

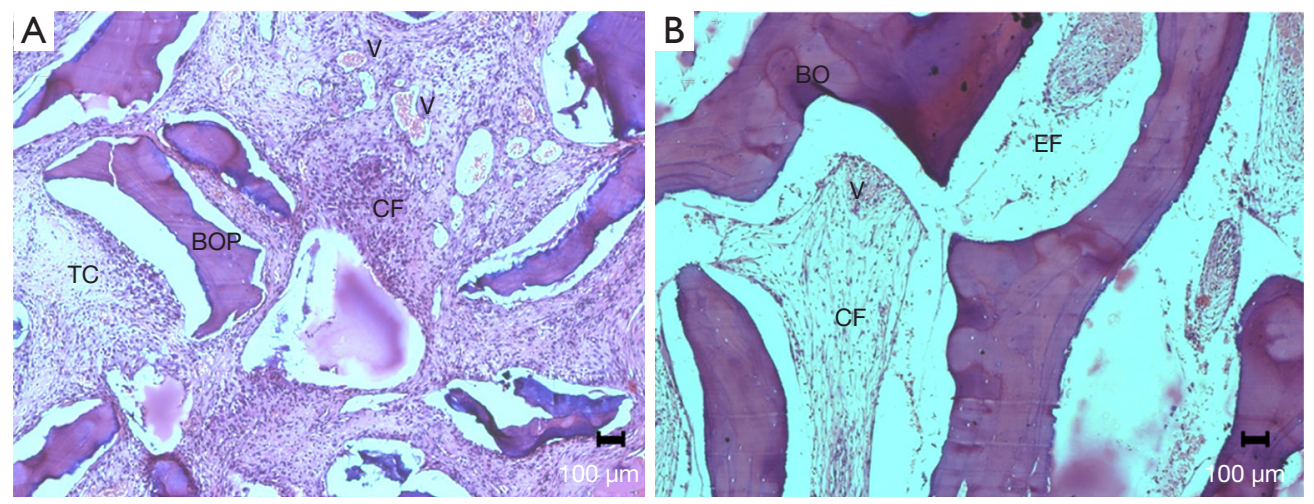

Figure 6 Subcutaneous tissue at 15 days showing particulate biomaterial (BOP) surrounded by connective tissue (CT) (A), and block biomaterial (BO) showing the trabecular spaces (ET) filled with loose connective tissue (CF) (B). H\&E stain. Magnification of 12.5x.
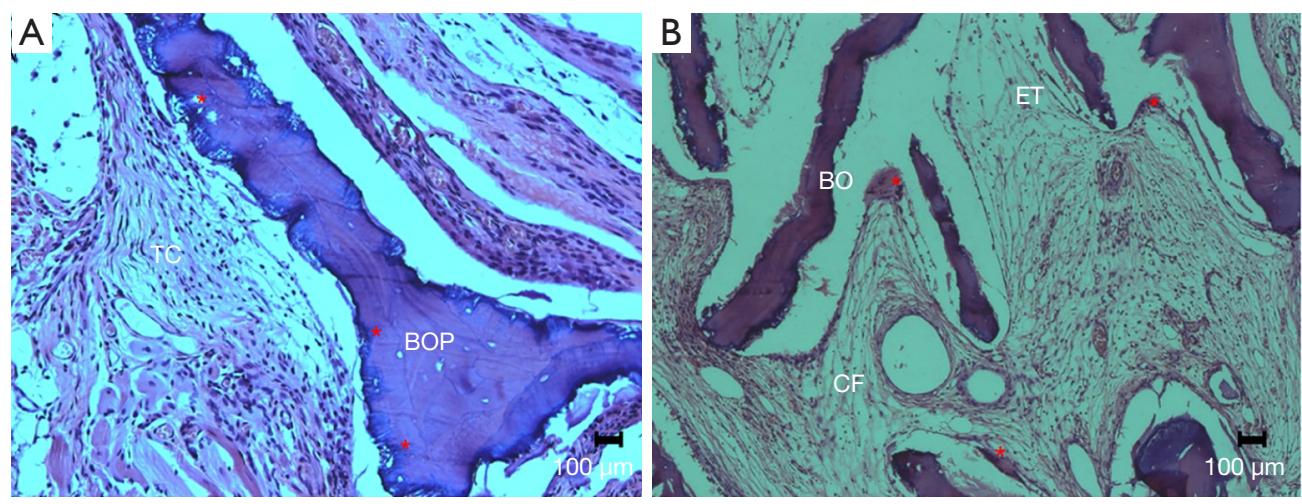

Figure 7 Subcutaneous tissue at 45 days showing fibrous connective tissue (CT) involving particulate biomaterial (BOP) and areas on its surface that suggest partial resorption (red asterisk); block biomaterial (BO) presenting its trabecular spaces (ET) filled with loose connective tissue (CF), and the presence of multinucleated giant cells in the vicinity of the implanted material (red asterisk) (B). H\&E stain. Magnification of $12.5 \times$.

\section{Discussion}

The methodology used in this study aimed to characterize the integral bone (Orthogen, Baumer S/A) regarding its biological activity, biocompatibility and osteopromotor potentital. For this purpose, a critical defect was made in the animal calvaria to evaluate the osteopromotor potential; additionally, the subcutaneous or muscular plane, which is characterized by being a non-skeletal site, was used to evaluate the osteoinduction activity of the biomaterial $(19,27)$.

\section{Critical defect}

The experimental model of the critical bone defect created in the skull cap of rats allows the evaluation of the specific biocompatibility of the implanted material, which constitutes a prerequisite for the safety and efficacy of the clinical indication of a product (18).

In the first part of this study, no bone neoformation activity was observed when evaluating a bone cavity, such as the calvary of rats that shows the presence of pre-osteogenic cells and osteoblasts. It is suggested that there will be bone neoformation with a greater or lower speed of neoformation depending on the use of biomaterials $(28,29)$ and on the functioning of the endocrine disorders $(30,31)$.

The results obtained in this study corroborate with others studys in the literature in which biomaterials of xenogenic origen ewere used in critical defects, and despite showing interaction with the repair process, they did not 
induce bone neoformation (32). However, he disagrees with the results found by Santos Kotake et al. (33) who demonstrated that xenogenous biomaterials can play a positive role to new bone formation.

The repair process did not show histological changes from the first to the second observation period, with no newly formed bone tissue and growth of fibrous connective tissue involving the remaining particles.

As regards histometric analysis, the results of this work were different from those obtained by Mendes et al. (34), who suggested the osteoconductive activity of the material, as it did not allow the development of bone tissue along the surface of the biomaterial; therefore, the clinical application must be such that the technique used and the indications for use be optimal for the material, fact also concluded in a comparative study between xenogenous biomaterials and synthetic nano-hydroxyapatite/beta-tricalcium phosphate composite $(28,29,35)$.

The optimization in the use of a bone substitute aims for the following: the material must be manipulated to fill cavities, it must be stable, since the micro-movement can induce the formation of fibrous connective tissue in its surroundings or cause foreign body reaction, which may have been a limitation of the study, and it must be protected by the membrane to prevent the proliferation of unwanted cells $(3,36,37)$.

\section{Subcutaneous plane}

The possibility that a lyophilized, demineralized, homogeneous, or heterogeneous material has osteoinductive potential has been suggested by some authors (38-40) and refuted by others $(41,42)$. These opposing results suggest that depending on the origin, the industrial process, and the age of the donor, active growth factors may be present that would cause ectopic bone formation. The results obtained in this study did not show ectopic bone formation on postoperative days 15 and 45 .

Regarding the cellular events observed in this study, moderate inflammatory infiltrate was observed at day 15 in the vicinity of the implanted composite bone particles, associated with the surgical procedure and the presence of foreign material in the subcutaneous plane, confirming results obtained in other studies that evaluated the biocompatibility of biomaterials and also concluded that, although bone substitutes have biocompatibility properties, ectopic bone formation was not found $(41,42)$.

In the groups of particulate or block of integral bone, a difference was observed between the tissues that involved the implanted materials at day 15 . In the particulate Orthogen group, there was an acute inflammatory reaction of mild intensity and, predominantly, there was loose connective tissue surrounding the particles, while in the Orthogen block group, no acute inflammatory infiltrates were observed. The justification for this difference may be linked to the fact that the particles implanted in the muscular plane would have lesser stability on muscular movements than the material implanted in the form of a block. This suggestion is based on the statement by Dahlin et al. (43) that micro-movements of the implanted material can prevent tissue organization.

At 45 days, in the composite bone group, there was a decrease in the polymorphonuclear neutrophils and a greater amount of collagenous matrix deposited around the material particles, indicating encapsulation, even though there were still a large number of multinucleated cells around the inorganic materials. There were no particles of organic material, suggesting its reabsorption.

Although the methodology of this study did not enable measurement of the volume of the implanted materials, it was possible to observe that in the 45-day group, there was partial reabsorption both in the particulate material and in the block. This fact requires proof in the bone cavity sites because if these occurrences persist, it is inferred that the grafts may undergo volume changes, especially when used in sinus grafts, alveolar cavities (particulate matter), or for horizontal or vertical enlargement with fixation (block material).

These results are similar to those presented by Sanada et al. (41) and Greghi et al. (44), who did not find ectopic bone neoformation activity with inorganic or organic materials, respectively. Nevertheless, a gradual decrease in the inflammatory cells and formation of fibrous connective tissue around the implanted materials indicates that the material has good biological acceptance.

\section{Conclusions}

Based on the methodology and results obtained in this study, it can be concluded that the integral bone of bovine origin is a biocompatible material but do not demonstrate potential to induce the bone neoformation, being contraindicate for GBR procedures.

\section{Acknowledgments}

Funding: None. 


\section{Footnote}

Provenance and Peer Review: This article was commissioned by the Guest Editors (Valfrido Antônio Pereira-Filho and Pedro Carvalho) for the series "Xenogenous and Xenosynthetic Bone Substitutes: State-of-the-art and Clinical Outcome" published in Frontiers of Oral and Maxillofacial Medicine. The article has undergone external peer review.

Reporting Checklist: The authors have completed the ARRIVE reporting checklist. Available at https://fomm. amegroups.com/article/view/10.21037/fomm-21-42/rc

Data Sharing Statement: Available at https://fomm. amegroups.com/article/view/10.21037/fomm-21-42/dss

Conflicts of Interest: All authors have completed the ICMJE uniform disclosure form (avaliable at https://fomm. amegroups.com/article/view/10.21037/fomm-21-42/ coif). The series "Xenogenous and Xeno-synthetic Bone Substitutes: State-of-the-art and Clinical Outcome" was commissioned by the editorial office without any funding or sponsorship. The authors have no other conflicts of interest to declare.

Ethical Statement: The authors are accountable for all aspects of the work in ensuring that questions related to the accuracy or integrity of any part of the work are appropriately investigated and resolved. Experiments were performed under a project license number: 201100893 granted by CEUA (ethics committee on animal use) Araçatuba Dental School - UNESP, in compliance with CONCEA, national guidelines for the care and use of animals.

Open Access Statement: This is an Open Access article distributed in accordance with the Creative Commons Attribution-NonCommercial-NoDerivs 4.0 International License (CC BY-NC-ND 4.0), which permits the noncommercial replication and distribution of the article with the strict proviso that no changes or edits are made and the original work is properly cited (including links to both the formal publication through the relevant DOI and the license). See: https://creativecommons.org/licenses/by-nc-nd/4.0/.

\section{References}

1. Cho YS, Hwang KG, Jun SH, et al. Radiologic comparative analysis between saline and platelet-rich fibrin filling after hydraulic transcrestal sinus lifting without adjunctive bone graft: A randomized controlled trial. Clin Oral Implants Res 2020;31:1087-93.

2. Minetti E, Palermo A, Savadori P, et al. Autologous tooth graft: a histological comparison between dentin mixed with xenograft and dentin alone grafts in socket preservation. J Biol Regul Homeost Agents 2019;33:189-97.

3. Urban IA, Monje A. Guided Bone Regeneration in Alveolar Bone Reconstruction. Oral Maxillofac Surg Clin North Am 2019;31:331-8.

4. Farnezi Bassi AP, Bizelli VF, Brasil LFM, et al. Is the Bacterial Cellulose Membrane Feasible for Osteopromotive Property? Membranes (Basel) 2020;10:230.

5. Farnezi Bassi AP, Ferreira Bizelli V, Mello Francatti T, et al. Bone Regeneration Assessment of Polycaprolactone Membrane on Critical-Size Defects in Rat Calvaria. Membranes (Basel) 2021;11:124.

6. Williams DF. Revisting the definition of biocompatibility material. Matteres Columm 2003;14:10-3.

7. Salata LA, Hatton PV, Devlin AJ, et al. In vitro and in vivo evaluation of e-PTFE and alkali-cellulose membranes for guided bone regeneration. Clin Oral Implants Res 2001;12:62-8.

8. Marx RE. Bone and bone graft healing. Oral Maxillofac Surg Clin North Am 2007;19:455-66, v.

9. Mann FA, Payne JT. Bone healing. Semin Vet Med Surg Small Anim 1989;4:312-21.

10. Sheikh Z, Qureshi J, Alshahrani AM, et al. Collagen based barrier membranes for periodontal guided bone regeneration applications. Odontology 2017;105:1-12.

11. Sheikh Z, Hamdan N, Ikeda Y, et al. Natural graft tissues and synthetic biomaterials for periodontal and alveolar bone reconstructive applications: a review. Biomater Res 2017;21:9.

12. Lynch SE, Genco RJ, Marx RE. Tissue engineering: applications in maxillofacial surgery and periodontics. Available online: http://www.quintpub.com/display_detail. php3?psku=B3466\#.YQanKY4zbIU

13. Danieletto-Zanna CF, Bizelli VF, Ramires GADA, et al. Osteopromotion Capacity of Bovine Cortical Membranes in Critical Defects of Rat Calvaria: Histological and Immunohistochemical Analysis. Int J Biomater 2020;2020:6426702.

14. Araújo CRG, Astarita C, D'Aquino R, et al. Evaluation of Bone Regeneration in Rat Calvaria Using Bone Autologous Micrografts and Xenografts: Histological 
and Histomorphometric Analysis. Materials (Basel) 2020;13:4284.

15. Oortgiesen DA, Plachokova AS, Geenen C, et al. Alkaline phosphatase immobilization onto Bio-Gide ${ }^{\circledR}$ and BioOss® for periodontal and bone regeneration. J Clin Periodontol 2012;39:546-55.

16. de Freitas Silva L, de Carvalho Reis ENR, Barbara TA, et al. Assessment of bone repair in critical-size defect in the calvarium of rats after the implantation of tricalcium phosphate beta ( $\beta$-TCP). Acta Histochem 2017;119:624-31.

17. Percie du Sert N, Ahluwalia A, Alam S, et al. Reporting animal research: Explanation and elaboration for the ARRIVE guidelines 2.0. PLoS Biol 2020;18:e3000411.

18. Vajgel A, Mardas N, Farias BC, et al. A systematic review on the critical size defect model. Clin Oral Implants Res 2014;25:879-93.

19. Khorramirouz R, Go JL, Noble C, et al. A novel surgical technique for a rat subcutaneous implantation of a tissue engineered scaffold. Acta Histochem 2018;120:282-91.

20. Hassumi JS, Mulinari-Santos G, Fabris ALDS, et al. Alveolar bone healing in rats: micro-CT, immunohistochemical and molecular analysis. J Appl Oral Sci 2018;26:e20170326.

21. Ramalho-Ferreira G, Faverani LP, Prado FB, et al. Raloxifene enhances peri-implant bone healing in osteoporotic rats. Int J Oral Maxillofac Surg 2015;44:798-805.

22. Faverani LP, Polo TOB, Ramalho-Ferreira G, et al. Raloxifene but not alendronate can compensate the impaired osseointegration in osteoporotic rats. Clin Oral Investig 2018;22:255-65.

23. Biguetti CC, De Oliva AH, Healy K, et al. Medicationrelated osteonecrosis of the jaws after tooth extraction in senescent female mice treated with zoledronic acid: Microtomographic, histological and immunohistochemical characterization. PLoS One 2019;14:e0214173.

24. Yogui FC, Momesso GAC, Faverani LP, et al. A SERM increasing the expression of the osteoblastogenesis and mineralization-related proteins and improving quality of bone tissue in an experimental model of osteoporosis. J Appl Oral Sci 2018;26:e20170329.

25. Messora MR, Nagata MJ, Dornelles RC, et al. Bone healing in critical-size defects treated with platelet-rich plasma activated by two different methods. A histologic and histometric study in rat calvaria. J Periodontal Res 2008;43:723-9.

26. Mariano R, Messora M, de Morais A, et al. Bone healing in critical-size defects treated with platelet-rich plasma: a histologic and histometric study in the calvaria of diabetic rat. Oral Surg Oral Med Oral Pathol Oral Radiol Endod 2010;109:72-8.

27. García-Gareta E, Coathup MJ, Blunn GW. Osteoinduction of bone grafting materials for bone repair and regeneration. Bone 2015;81:112-21.

28. Schmidt LE, Hadad H, Vasconcelos IR, et al. Critical Defect Healing Assessment in Rat Calvaria Filled with Injectable Calcium Phosphate Cement. J Funct Biomater 2019;10:21.

29. Puttini IO, Poli PP, Maiorana C, et al. Evaluation of Osteoconduction of Biphasic Calcium Phosphate Ceramic in the Calvaria of Rats: Microscopic and Histometric Analysis. J Funct Biomater 2019;10:7.

30. Ramalho-Ferreira G, Faverani LP, Grossi-Oliveira GA, et al. Alveolar bone dynamics in osteoporotic rats treated with raloxifene or alendronate: confocal microscopy analysis. J Biomed Opt 2015;20:038003.

31. Ramalho-Ferreira G, Faverani LP, Momesso GAC, et al. Effect of antiresorptive drugs in the alveolar bone healing. A histometric and immunohistochemical study in ovariectomized rats. Clin Oral Investig 2017;21:1485-94.

32. Musson DS, Gao R, Watson M, et al. Bovine bone particulates containing bone anabolic factors as a potential xenogenic bone graft substitute. J Orthop Surg Res 2019;14:60.

33. Santos Kotake BG, Gonzaga MG, Coutinho-Netto J, et al. Bone repair of critical-sized defects in Wistar rats treated with autogenic, allogenic or xenogenic bone grafts alone or in combination with natural latex fraction F1. Biomed Mater 2018;13:025022.

34. Mendes SM, Fonseca CE, Bassi APF, et al. Histologic and histomorphometric evaluation of heterogenous demineralized bone or compound bone with and without bone morphogenetic protein $(\mathrm{BMP})$ in rat tíbia. Revista Odontológica de Araçatuba 2006;27:34-40.

35. da Silva Brum I, Frigo L, Lana Devita R, et al. Histomorphometric, Immunohistochemical, Ultrastructural Characterization of a NanoHydroxyapatite/Beta-Tricalcium Phosphate Composite and a Bone Xenograft in Sub-Critical Size Bone Defect in Rat Calvaria. Materials (Basel) 2020;13:4598.

36. Hermann JS, Buser D. Guided bone regeneration for dental implants. Curr Opin Periodontol 1996;3:168-77.

37. Patino MG, Neiders ME, Andreana S, et al. Cellular inflammatory response to porcine collagen membranes. J Periodontal Res 2003;38:458-64.

38. Li H, Pujic Z, Xiao Y, et al. Identification of bone 
morphogenetic proteins 2 and 4 in commercial demineralized freeze-dried bone allograft preparations: pilot study. Clin Implant Dent Relat Res 2000;2:110-7.

39. Urist MR. Bone: formation by autoinduction. Science 1965;150:893-9.

40. Lohmann CH, Andreacchio D, Köster G, et al. Tissue response and osteoinduction of human bone grafts in vivo. Arch Orthop Trauma Surg 2001;121:583-90.

41. Sanada JT, Rodrigues JG, Canova GC, et al. Histologic, radiographic and imunoglobuline profile analysis after implantation blocks of demineralized bovine cancellous bone graft in muscle of rats. J Appl Oral Sci 2003;11:209-15.

doi: $10.21037 /$ fomm-21-42

Cite this article as: Bassi APF, Bizelli VF, Consolaro RB, de Carvalho PSP. Biocompatibility and osteopromotor factor of bovine integral bone-a microscopic and histometric analysis. Front Oral Maxillofac Med 2021;3:33.
42. Zambuzzi WF, Neves MCM, Oliveira RC, et al. Tissue reaction and phosphatases profile after implant of xenogenic demineralized bone matrix in rat muscule. Cienc Odontol Bras 2005;8:90-8.

43. Dahlin C, Simion M, Nanmark U, et al. Histological morphology of the e-PTFE/tissue interface in humans subjected to guided bone regeneration in conjunction with oral implant treatment. Clin Oral Implants Res 1998;9:100-6.

44. Greghi SLA, Campos Junior A. Comparative study of various ceramics materials in subcutaneous connective tissue of rats. Rev FOB 1994;2:73-81. 